\title{
Mogućnost aklimatizacije jesenske sovice na području Zadarske županije
}

\section{Possible aclimatization of fall armyworm in Zadar county}

\author{
Martina Kadoić Balaško*, Monika Zlodi, Renata Bažok \\ Sveučilište u Zagrebu Agronomski fakultet, Zavod za poljoprivrednu zoologiju, Svetošimunska cesta 25, 10000 Zagreb \\ * Corresponding author E-mail address: mbalasko@agr.hr (M. Kadoić Balaško)
}

\section{Sažetak}

Jesenska sovica (Spodoptera frugiperda) značajan je polifagni štetnik iz porodice sovica. Potječe iz suptropskog i tropskog područja Amerike, gdje se smatra ekonomski važnim štetnikom na kultiviranim biljkama. Prvi je put, izvan američkog kontinenta, zabilježen u zapadnoj Africi početkom 2016. godine te se potom nastavio širiti prema Aziji i Australiji. Zbog velike mogućnosti migracije (odrasla sovica za vrijeme ljetnih mjeseci preleti do $2000 \mathrm{~km}$ ), ovaj štetnik bi se vrlo brzo mogao pojaviti i na području Mediterana. Uslijed klimatskih promjena i ekoloških zahtjeva jesenske sovice opravdana je sumnja da bi se ovaj štetnik mogao udomaćiti u Europi, ali i u Hrvatskoj. Na razvoj i širenje jesenske sovice najviše utječu temperature, oborine i dostupnost biljke domaćina. Cilj je rada prikazati biološke i ekološke osobine jesenske sovice, prikazati trenutni status u svijetu i utvrditi mogućnost aklimatizacije u području srednje Dalmacije (Zadar). S postaje Zadar prikupljeni su meteorološki podaci za razdoblje od 2010. do 2020. godine. Pogodnost područja određena je na temelju izračuna sume efektivnih temperatura potrebnih za razvoj jedne generacije (termalni prag $10,9{ }^{\circ} \mathrm{C}$, suma $559^{\circ} \mathrm{C}$ srednjih dnevnih temperatura iznad praga i mjesečna količina oborina ispod $100 \mathrm{~mm}$ ). Provedena analiza meteoroloških podataka i njihova usporedba sa zahtjevima štetnika pokazala je da aklimatizacija štetnika nije moguća, ali da zbog povoljnih uvjeta u proljetnom i ljetnom periodu postoji opasnost od sezonskih migracija jesenske sovice na područje Zadarske županije.

Ključne riječi: Spodoptera frugiperda, karantenski štetnik, klimatske promjene, Hrvatska

\begin{abstract}
The fall armyworm is an important polyphagous pest of the owlet moth's family. It is native to subtropical and tropical regions of the Americas, where it is considered an economically important pest of crops. Outside the Americas, it was first recorded in early 2016 at West Africa and then spread further into Asia and Australia. Due to the great possibility of migration (an adult moth flies over $2000 \mathrm{~km}$ in the summer months), this pest could appear very quickly in the Mediterranean region. Due to climate change and the ecological requirements of the fall armyworm, there is a reasonable suspicion that this pest could become established in Europe and Croatia. The development and spread of the fall armyworm are mainly influenced by temperatures, precipitation and the availability of the host plant. The aim of this work is to present the biological and ecological characteristics of the fall armyworm,
\end{abstract}


to present its current status in the world and to determine the possibility of acclimatization in the area of Central Dalmatia (Zadar). Meteorological data for the period from 2010 to 2020 were collected from the station in Zadar. The suitability of the area was determined by calculating the sum of effective temperatures required for the development of one generation (thermal threshold $10.9^{\circ} \mathrm{C}$, the sum of $559^{\circ} \mathrm{C}$ mean daily temperatures above the threshold and the monthly amount of precipitation below $100 \mathrm{~mm}$ ). The analysis of meteorological data and their comparison with the requirements of the pest showed that acclimatization of fall armyworm is not possible, but that due to the favorable conditions in spring and summer there is a risk of seasonal migration in Zadar County.

Keywords: Spodoptera frugiperda, quarantine pest, climate changes, Croatia

\section{Uvod - Introduction}

Jesenska sovica (Spodoptera frugiperda (J.E. Smith 1797)) porijeklom je iz suptropskog i tropskog područja Amerike, gdje se smatra ekonomski važnim štetnikom na kultiviranim biljkama (EPPO 2021) Polifagna je vrsta te je do sada zabilježeno gotovo 100 biljaka domaćina (FAO i CABI 2019). Štete rade gusjenice koje se najčešće hrane na kukuruzu, a napada i pšenicu, rižu, sirak, soju, šećernu trsku i pamuk. Štete su zabilježene i na rajčici, luku, krumpiru, ukrasnom bilju te agrumima (EPPO 2021). Procjenjuje se da uzrokuje štete u iznosu višem od 400 milijuna američkih dolara godišnje (IITA 2016). Velika mogućnosti migracije (odrasla sovica za vrijeme ljetnih mjeseci preleti i do $2000 \mathrm{~km}$ ), izrazita polifagnost i pojava više generacija godišnje omogućuju ovom štetniku brzo širenje i udomaćenje na novim prostorima (Jeger i sur. 2018).

Sagar i sur. (2020) navode kako je jesenska sovica iz Amerike u Afriku unesena zrakoplovom i putem teretnih kontejnera. Štetnik je prvi puta zabilježen u zapadnoj Africi početkom 2016. godine (EPPO 2017). Značajne štete na usjevima kukuruza zabilježene su odmah po unosu štetnika, a tijekom idućih dviju godina zbog svoje sposobnosti leta na velike udaljenosti sovica se proširila po cijelom subsaharskom području Afrike (EPPO 2021). Nakon što se proširila po afričkom kontinentu, 2018. godine zabilježena je i u Aziji. U svibnju iste godine jesenska sovica pronađena je u Indiji na usjevima kukuruza, sirka i prosa (EPPO 2018). Tijekom 2018. i 2019. godine sovica je prvi puta uočena u Kini, Myanmaru, Tajlandu, Bangladešu i Šri Lanci, a zabilježene su i prve značajne štete na usjevima kukuruza (EPPO 2019). Prema posljednjim podacima Europske i mediteranske organizacije za zaštitu bilja, štetnik se proširio po afričkom i azijskom kontinentu te u Australiju i Oceaniju (EPPO 2021). U lipnju 2019. godine štetnik je prvi puta zabilježen u Egiptu, a zatim u rujnu 2020. godine na poljima kukuruza u Jordanu, gdje do sada nisu prijavljene značajne štete (FAO i PPD 2020; EPPO 2020). Prisutnost jesenske sovice u Egiptu i Jordanu najbliže je Europi dosada.

Da bi jesenska sovica mogla proći cijeli životni ciklus, potrebne su temperature iznad temperaturnog praga od $10,9^{\circ} \mathrm{C}$ i suma efektivnih dnevnih temperatura od $559^{\circ} \mathrm{C}(\mathrm{Je}-$ ger i sur. 2018). Optimalna temperatura za razvoj gusjenica je $28^{\circ} \mathrm{C}$ (Assefa i Ayalewc 2019). Optimalni raspon temperatura za razvoj jaja, gusjenice i imaga iznosi $26-30{ }^{\circ} \mathrm{C}$, dok je minimalni temperaturni prag za razvoj jaja $13,01^{\circ} \mathrm{C}$ te za gusjenice i kukuljice on iznosi $12,12{ }^{\circ} \mathrm{C}$, odnosno $13,06{ }^{\circ} \mathrm{C}$ (Du Plessis i sur. 2020). Baloch i sur. (2020) navode da kada je mjesečna količina oborina iznad $100 \mathrm{~mm}$, dolazi do smanjene pojave štetnika. Kako se odrasle gusjenice jesenske sovice nalaze u pazušcima listova biljaka domaćina, tijekom većih količina oborina one se „utope“. 
Prema EPPO (2017) jesenska sovica nalazi se na A1 listi karantenskih štetnika za Europu, što znači da štetnik nije prisutan na području EPPO zone. Direktivom Vijeća 200/29/EC jesenska sovica regulirana je kao karantenski štetnik čije je unošenje i širenje zabranjeno na prostoru Europske unije. U slučaju udomaćenja jesenske sovice na južnom području Europske unije procjenjuje se kako bi mogla prouzročiti velike štete i gubitke prinosa na usjevima kukuruza, riže i prvenstveno sirka (Kinklar i sur. 2020). Uslijed klimatskih promjena i ekoloških zahtjeva jesenske sovice, opravdana je sumnja da bi se ovaj štetnik mogao udomaćiti u Europi (Jeger i sur. 2017), ali i u Hrvatskoj.

Cilj ovog rada bio je analizirati dostupne podatke o ekološkim zahtjevima jesenske sovice (temperatura i vlaga) te ih usporediti s klimatskim uvjetima na području srednje Dalmacije (Zadar) i procijeniti mogućnost aklimatizacije.

\section{Materijali i metode - Material and Methods}

Zadar se nalazi na $44^{\circ} 07^{\prime}$ sjeverne zemljopisne širine i $15^{\circ} 13^{\prime}$ istočne zemljopisne dužine. Nalazi se na istočnoj obali Jadranskog mora, u području sjeverne Dalmacije. Područje grada Zadra reljefno pripada mladom dinarskom sustavu gorja i predgorskih prostora koji se pruža u pravcu sjeverozapad-jugoistok. Cjelokupno područje Grada Zadra pripada sredozemnoj klimi sa suhim i vrućim ljetima te vlažnim i blagim zimama (Miletić, 2018).

Za izradu procjene aklimatizacije jesenske sovice za Republiku Hrvatsku (klimatska postaja Zadar) prikupljeni su podaci o ukupnim mjesečnim količinama oborina i srednjim dnevnim temperaturama zraka u razdoblju od 1.1.2010. godine do 31.12.2020 godine. Tražene podatke za područje Zadra dostavio nam je Državni hidrometeorološki zavod (DHMZ).

Podatke za procjenu aklimatizacije jesenske sovice analizirali smo u programu za tablično računanje Microsoft Excel. Izračun efektivnih prosječnih srednjih mjesečnih temperatura zraka u zimskim mjesecima (od studenog do veljače) i u proljetnim i ljetnim mjesecima (od travnja do kolovoza) bio je temelj za procjenu mogućnosti prezimljenja i razvoja štetnika na području Zadra u razdoblju od 2010. do 2020. godine. Glavni kriteriji pomoću kojih smo odredili postoji li mogućnost aklimatizacije jesenske sovice bili su termalni prag od $10,9^{\circ} \mathrm{C}$, suma efektivnih dnevnih temperatura iznad $559{ }^{\circ} \mathrm{C}$ i prosječna mjesečna količina oborina ispod $100 \mathrm{~mm}$. Za izračun efektivnih prosječnih srednjih mjesečnih temperatura korištene su srednje dnevne temperature zraka umanjene za termalni prag.

Za izračun mogućeg broja generacija jesenske sovice na području Zadra zbrojene su srednje efektivne dnevne temperature zraka (iznad termalnog praga) u razdoblju od 1.1. do 31.12. za svaku godinu do sume efektivnih temperatura od $559{ }^{\circ} \mathrm{C}$ koja je potrebna za razvoj jedne generacije.

Od svih 12 mjeseci od 2010. godine do 2020. godine za mjesečnu količinu oborina izdvojili smo mjesece travanj, svibanj, lipanj, srpanj, kolovoz, kao period vegetacije kukuruza ujedno i najvjerojatnijeg domaćina jesenske sovice u Hrvatskoj.

\section{Rezultati i rasprava - Results and discussion}

Slikom 1. prikazani su zimski mjeseci tijekom kojih temperatura pada ispod termalnog praga te razvoj i prezimljenje štetnika nije moguće. 


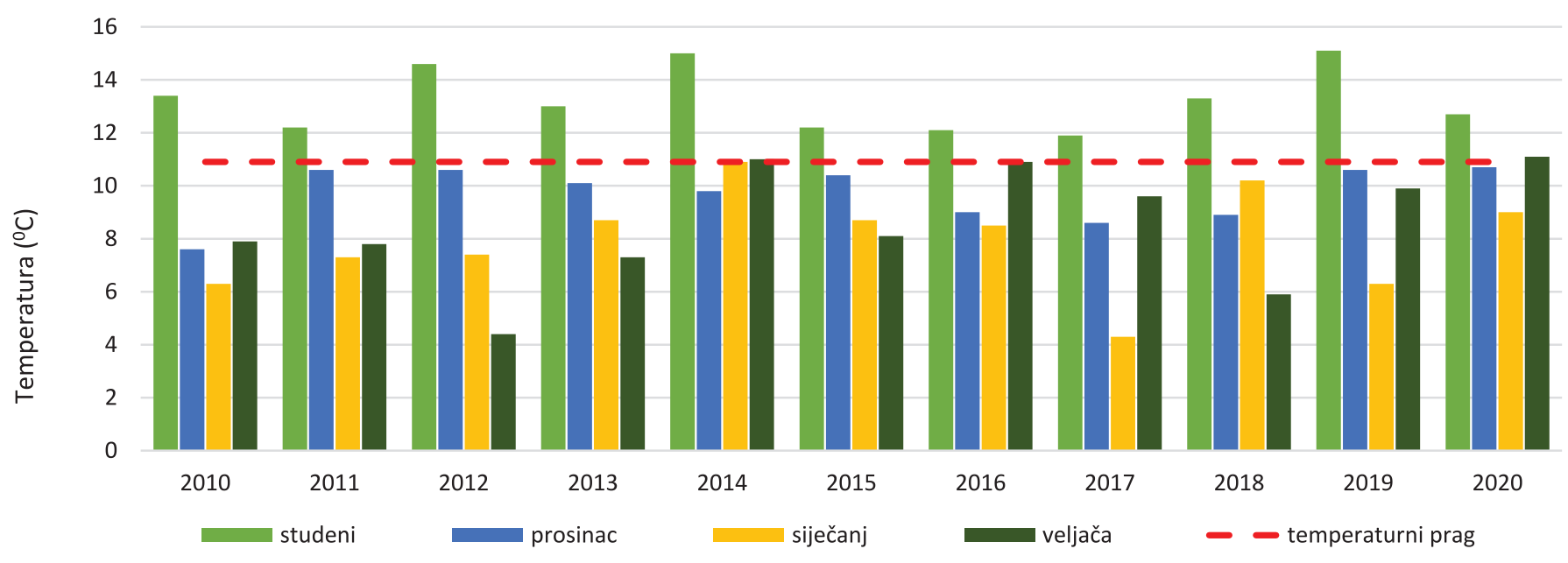

Slika 1. Prosječna srednja temperatura zraka u studenom, prosincu, siječnju i veljači u razdoblju od 2010. do 2020. godine na meteorološkoj postaji Zadar.

Figure 1. Average monthly air temperature in November, December, January and February in the period from 2010 to 2020 at the meteorological station Zadar

Na slici 2. na osnovi srednjih dnevnih temperatura zraka u posljednjih 10 godina prikazani su najpogodniji mjeseci za razvoj štetnika na lokalitetu Zadar. Iz slike je vidljivo da su temperature tijekom proljetnih i ljetnih mjeseci iznad termalnog praga razvoja. Temperature u ljetnim mjesecima (od lipnja do kolovoza) na području Zadra kreću se u prosjeku između $20^{\circ} \mathrm{C}$ i $27^{\circ} \mathrm{C}$ što je povoljno za razvoj jesenske sovice.

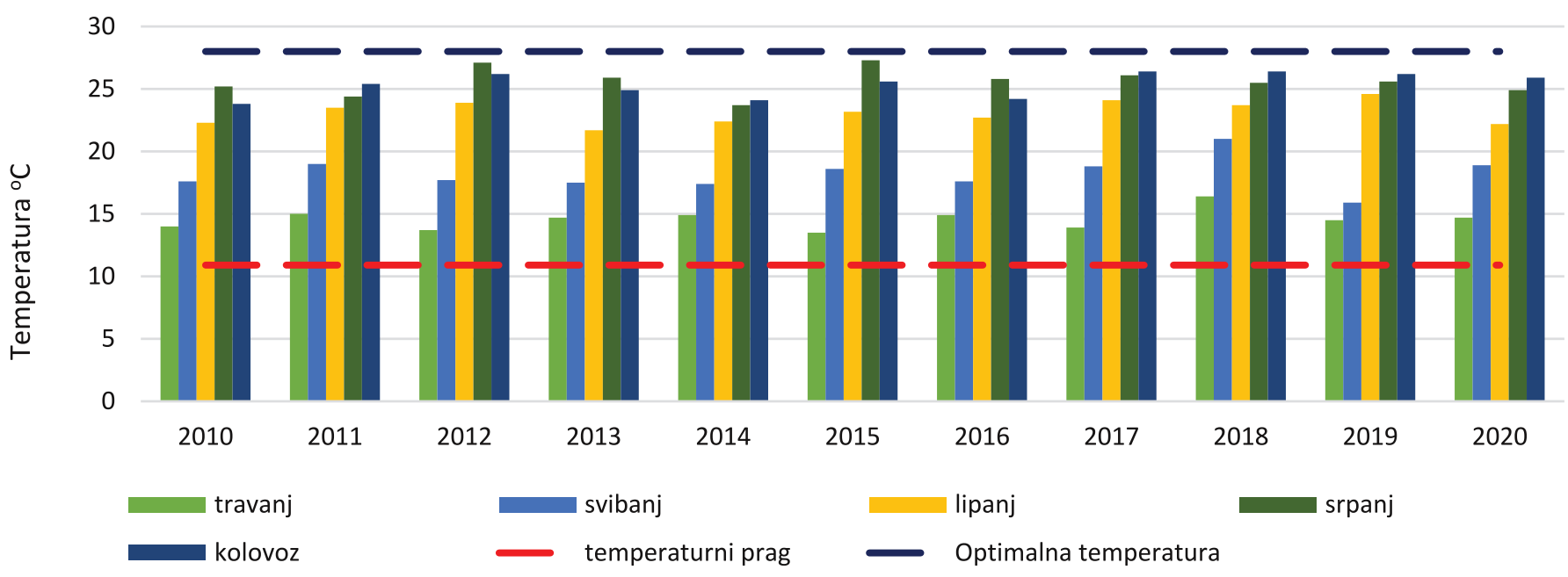

Slika 2. Prosječna srednja mjesečna temperatura zraka u travnju, svibnju, lipnju, srpnju i kolovozu u razdoblju od 2010. do 2020. godine na meteorološkoj postaji Zadar

Figure 2. Average monthly air temperature in April, May, June, July and August in the period from 2010 to 2020 at the meteorological station Zadar

Nakon provedene analize podataka, utvrđeno je da jesenska sovica može preživjeti i razvijati se na području Zadra, međutim ne postoje odgovarajući uvjeti za njezino prezimljenje i razvoj tijekom zimskih mjeseci.

Analizom mjesečne količine oborina u razdoblju od 2010. do 2020. godine za mjesece travanj, svibanj, lipanj, srpanj i kolovoz utvrđeno je da je količina oborina prikladna za razvoj jesenske sovice (slika 3.). 


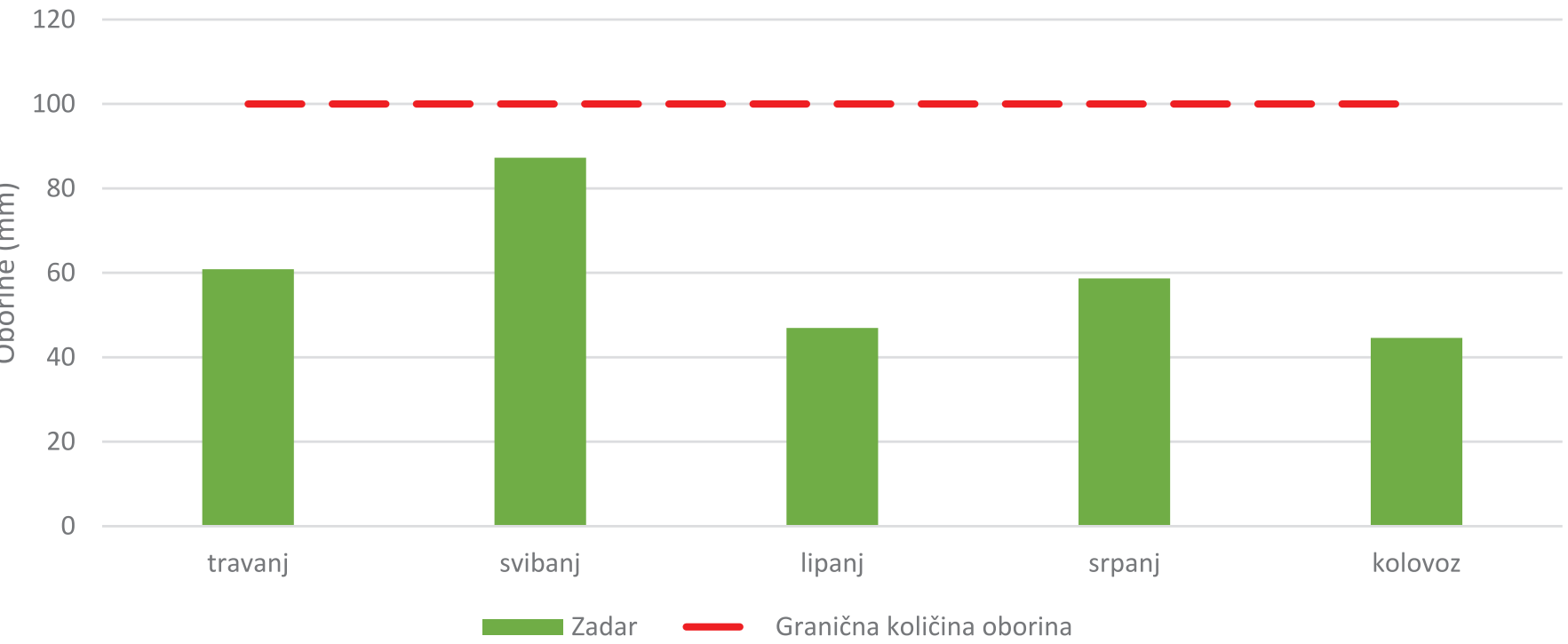

Slika 3. Ukupna prosječna količina oborina tijekom travanja, svibnja, lipnja, srpnja i kolovoza na meteorološkoj postaji Zadar u razdoblju od 2010. do 2020. godine.

Figure 3. Average total precipitation in the months of April, May, June, July, August at meteorological station Zadar in the period from 2010 to 2020

U slučaju aklimatizacije jesenske sovice važno je znati koliko bi generacija mogla razviti na određenom području. Tablicom 1. prikazani su teoretski datumi pojave jesenske sovice na lokalitetu Zadar. Za izračun je uzet prosjek tijekom posljednjih 10 godina na temelju sume efektivnih temperatura.

Tablica 1. Teoretski datumi pojave jesenske sovice na lokalitetu Zadar.

Table 1. Teoretical dates of the appearance of fall armyworm at the site Zadar

\begin{tabular}{cc}
\hline & Očekivana pojava štetnika \\
\hline 1. generacija & $12.4 .-2.5$. \\
\hline 2. generacija & $16.5 .-1.6$. \\
\hline 3. generacija & $14.6 .-26.6$. \\
\hline 4. generacija & $7.7 .-18.7$ \\
\hline 5. generacija & $30.7 .-11.8$. \\
\hline 6. generacija & $21.8 .-5.9$. \\
\hline 7. generacija & $14.9 .-4.10$.
\end{tabular}

Analizom podataka utvrđeno je da optimalna temperatura za razvoj jesenske sovice, $28^{\circ} \mathrm{C}$, nije zabilježena (slika 2.). Wang i sur. (2020) navode da se temperature koje su povoljne za razvoj i razmnožavanje jesenske sovice kreću od $20{ }^{\circ} \mathrm{C}$ do $32{ }^{\circ} \mathrm{C}$. Prema provedenoj analizi podataka utvrđeno je da su temperature u ljetnim mjesecima na području postaje Zadar (slika 2.) povoljne za razvoj štetnika, a kreću se od $20{ }^{\circ} \mathrm{C}$ do $27^{\circ} \mathrm{C}$. S obzirom na to da Zadar geografski pripada sredozemnoj klimi sa suhim i vrućim ljetima te vlažnim i blagim zimama, za očekivati je da je ovo područje koje bi odgovaralo jesenskoj sovici. Ipak, temeperature u zimskim mjesecima preniske su da bi štetnik mogao prezimiti i nastaviti svoj razvoj (slika 1). Štetnik ne podnosi tempera- 
ture ispod $10{ }^{\circ} \mathrm{C}$ dva ili više dana (Assefa i Ayalewc 2019), a na temperaturama ispod $0{ }^{\circ} \mathrm{C}$ odmah dolazi do uginuća (CABI 2020). Osim temperature, važno je i prisustvo biljke domaćina kojeg štetnik preferira, a to je kukuruz. Na području Zadarske županije, koje je prema temperaturama povoljno za razvoj štetnika, pod kukuruzom je oko 400 ha (Statistički ljetopis, 2018), što nije puno u odnosu na Istočnu i Središnju Hrvatsku, ali je dovoljno za preživljavanje štetnika i moguće širenje dalje prema sjeveru. U slučaju udomaćenja jesenske sovice štete na kukuruzu, ali i drugim kulturama, mogle bi biti velike jer štetnik u područjima gdje je prisutan razvija više generacija koje se preklapaju (Wang i sur. 2020).

Pod pretpostavkom da je štetnik prisutan na području Zadra i na temelju izračuna sume efektivnih temperatura, dobili smo da jesenska sovica teoretski može razviti do sedam generacija. Razvoj prve generacije očekuje se između 12.4. i 2.5. Međutim, zbog nemogućnosti prezimljenja, a sposobnosti leta na velike udaljenosti pretpostavka je da bi štetnik mogao doletjeti iz područja gdje je trenutno prisutan najbliže Europi (Egipat, Jordan) na područje Zadarske županije (Jeger, 2017). U tom slučaju teško je prognozirati koliko bi generacija štetnik mogao razviti jer migracije mogu varirati iz godine u godinu te ovise o više faktora. Jeger i sur. (2017) procijenili su da bi jesenska sovica u slučaju sezonskih migracija na području Mediterana mogla razviti 3 do 4 generacije.

Aklimatizacija podrazumijeva prilagodbu nekog organizma podneblju i geografskom području. U ovom radu utvrđeno je da aklimatizacija jesenske sovice na području Zadarske županije trenutno nije moguća, ali da zbog povoljnih klimatskih uvjeta u ljetnim mjesecima i dostupnosti biljke domaćina ipak postoji opasnost od sezonskih migracija.

\section{Zaključak - Conclusion}

Jesenska sovica polifagan je štetnik, u povoljnim uvjetima ima visoki biološki potencijal te veliku sposobnost preživljavanja. S obzirom na pojavu štetnika u sjevernoj Africi i zapadnoj Aziji, predstavlja ozbiljnu prijetnju proširenja na europski kontinent, a time i prijetnju proizvodnji kukuruza u Europi. Prognoza aklimatizacije jesenske sovice u Hrvatskoj vrlo je važna.

Važna stavka u procjeni aklimatizacije štetnika su i sveprisutne klimatske promjene kojima svjedočimo, a koje dokazano utječu na promjenu areala rasprostranjenja štetnika. Porastom temperature i smanjenjem količine oborina istraživani lokaliteti postat će još prikladniji za preživljavanje jesenske sovice uz moguće prezimljenje (Zadar) i povećanje broja generacija tijekom godine. Procjena mogućnosti aklimatizacije obavlja se da bi se u slučaju udomaćenja štetnika mogli predvidjeti lokaliteti i razdoblje aktivnosti te potencijalna štetnost. Od iznimne je važnosti nastaviti kontinuirane kontrole kako bi se spriječio slučajan unos ovog štetnika u Europu. Također, važno je upoznati i educirati poljoprivrednike o jesenskoj sovici kako bi ju mogli na vrijeme prepoznati i djelovati u trenutku njezine pojave u usjevima. 


\section{Literatura - References}

Assefa, F., Ayalewc, D. 2019. Status and control measures of fall armyworm (Spodoptera frugiperda) infestations in maize fields in Ethiopia: A review. Cogent Food and Agriculture. 5: 1641902.

Baloch, M.N., Fan, J., Haseeb, M., Zhang, R. 2020. Mapping Potential Distribution of Spodoptera frugiperda (Lepidoptera: Noctuidae) in Central Asia. Insects. 11 (3): 172.

DIREKTIVA VIJEĆA 2000/29/EC od 8. svibnja 2000. o zaštitnim mjerama protiv unošenja u Zajednicu organizama štetnih za bilje ili biljne proizvode i protiv njihovog širenja unutar Zajednice. Službeni list Europske unije 169. 10/07/2000 P. $0001-0112$

DRŽAVNI ZAVOD ZA STATISTIKU. 2018. Statistički ljetopis Republike Hrvatske 2018. Zagreb: Državni zavod za statistiku. https://www.dzs.hr/Hrv_Eng/ljetopis/2018/sljh2018.pdf (pristupljeno: 30. kolovoza 2021.)

Du Plessis, H., Schlemmer, M.L., Van Den Berg, J. 2020. The Effect of Temperature on the Development of Spodoptera frugiperda (Lepidoptera: Noctuidae). Insects. 11: 228.

EPPO. 2017. EPPO Global Database. EPPO - European and Mediterranean Plant Protection Organization. Spodoptera frugiperda continues to spread in Africa. EPPO Reporting Service no. 02 - 2017. https:/ /gd.eppo.int/reporting/article-6003 (pristupljeno: 22. travnja 2021.)

EPPO. 2018. EPPO Global Database. EPPO - European and Mediterranean Plant Protection Organization. First report of Spodoptera frugiperda in India. EPPO Reporting Service no. 08 - 2018. https:/ /gd.eppo.int/reporting/article-6348 (pristupljeno: 22. travnja 2021.)

EPPO. 2019. EPPO Global Database. EPPO - European and Mediterranean Plant Protection Organization. Spodoptera frugiperda continues to spread in Asia. EPPO Reporting Service no. 03 - 2019. https://gd.eppo.int/reporting/article-6483 (pristupljeno: 22. travnja 2021.)

EPPO. 2020. EPPO Global Database. EPPO - European and Mediterranean Plant Protection Organization. First report of Spodoptera frugiperda in Australia. EPPO Reporting Service no. 02 - 2020. https://gd.eppo.int/reporting/article-6709 (pristupljeno: 22. travnja 2021.)

EPPO. 2021. EPPO Global Database. EPPO - European and Mediterranean Plant Protection Organization. https://gd.eppo. int (pristupljeno: 15. lipnja 2021.)

FAO i CABI. 2019. Community Based Fall Armyworm (Spodoptera frugiperda) Monitoring, Early Warning and Management. Training of Trainer Manual (First Edition).

FAO i PPD. 2020. Manual on Integrated fall armyworm management. Yangon, FAO.

IITA. 2016. IITA Headquarters. IITA - The International Institute of Tropical Agriculture. First report of outbreaks of the "Fall Armyworm" on the African continent. IITA Bulletin, No. 2330. http:/ / bulletin.iita.org/index.php/2016/06/18/ first-report-of-outbreaks-of-the-fall-armyworm-on-the-african-continent/ (pristupljeno: 23. travnja 2021.)

Jeger, M., Bragard, C., Caffier, D., Candresse, T., Chatzivassiliou, E., Dehnen-Schmutz, K., Gilioli, G., Gregoire, J.C., Jaques Miret, J.A., Navarro, M.N., Niere, B., Parnell, S., Potting, R., Rafoss, T., Rossi, V., Urek, G., Van Bruggen, A., Van Der Werf, W., West, J., Winter, S., Gardi, C., Aukhojee, M., Macleod, A. 2017. Pest categorisation of Spodoptera frugiperda. EFSA Journal. 15 (7): 4927.

Jeger, M., Bragard, C., Caffier, D., Candresse, T., Chatzivassiliou, E., Dehnen-Schmutz, K., Giliol, I.G., Gregoire, J.C., Jaques Miret, J.A., Navarro, M.N., Niere, B., Parnell, S., Potting, R., Rafoss, T., Rossi, V., Urek, G., Van Bruggen, A., Van Der Werf, W., West, J., Winter, S., Day, R., Early, R., Hruska, A., Nagoshi, R., Gardi, C., Mosbach-Schultz, O., Macleod, A. 2018. Scientific Opinion on the pest risk assessment of Spodoptera frugiperda for the European Union. EFSA Journal. 16 (8): 5351.

Kinklar, M., Delbianco, M., Vos, S. 2020. Pest survey card on Spodoptera frugiperda. EFSA Journal. EFSA Supporting Publications. 17 (7): 1895E.

Miletić, J. 2018. Razvojne mogućnosti zadarskog turizma u Zadarskoj županiji s posebnim osvrtom na Ninsko blato. Doktorska disertacija, Sveučilište u Zadru.

Sagar, G.C., Aastha, B.I., Laxman, K. 2020. An introduction of fall armyworm (Spodoptera frugiperda) with management strategies: a review paper. Nippon Journal of Environmental Science. 1 (4): 1010.

Wang, R., Jiang, C., Guo, X., Chen, D., You, C., Zhang, Y., Wang, M., Li, Q. 2020. Potential distribution of Spodoptera frugiper$d a$ (J.E. Smith) in China and the major factors influencing distribution. Global Ecology and Conservation. 21: e00865. 